\title{
DETERMINANTS OF DRIVING AFTER STROKE
}

\author{
Abiodun Emmanuel Akinwuntan, Hilde Feys, Willy De Weerdt \\ Department of Rehabilitation Sciences \\ Faculty of Physical Education and Physiotherapy \\ Katholieke Universiteit Leuven \\ Belgium \\ Jan Pauwels \\ Department of Kinesiology \\ Faculty of Physical Education and Physiotherapy \\ Katholieke Universiteit Leuven \\ Belgium \\ Guido Baten, Emmanuel Strypstein \\ CARA \\ Belgian Institute for Road Safety \\ Brussels \\ Belgium
}

\begin{abstract}
Summary: Objective: To identify from a predriving assessment the tests that best predict the driving ability of stroke patients. Design: Examination of records of 104 first ever stroke patients who visited the Belgian Institute for Road Safety in 1998 and 1999 and performed the medical, visual, perceptual and the 'on the road' assessments. Measures: Variables such as age, sex, side of lesion, driving experience, visual tests, neuropsychological assessments most of which are from the Test for Attentional Performance (TAP) battery and an 'on the road' test were considered. Based on performances of subjects on the tests, a suitable, not immediately suitable or not suitable to drive decision was jointly taken by the team of assessors. Results: Following a logistic regression analysis, a combination of side of lesion, kinetic vision, visual scanning and the 'on the road' tests led to the best model in predicting the final group decision $\left(\mathrm{R}^{2}=0.53\right)$. The 'on the road' test was the most important determinant $\left(\mathrm{R}^{2}=0.42\right)$. Conclusion: The predictive accuracy of the decision is moderate. Inclusion of assessments more closely related to real road situations should be considered.
\end{abstract}

\section{INTRODUCTION}

Stroke was reported to be the third major cause of death and a major source of disability in the United States (Duncan et al, 1992). The incidence of primary stroke in Britain is around 2 per 1000 population per year, a quarter occurring in those aged under 65 years (Bramford et al, 1988). In Belgium, the incidence of stroke is estimated at 2.62 per 1000 population annually (Van Casteren et al, 1988). A neurologic event such as stroke affects driving ability (Mazer et al, 1998). Victims present various physical and neuropsychological impairments such as motor, speech, visual, cognitive and perceptual problems of which some represent definite symptoms 
contrary to driving (Sundet et al, 1995). A well-configured predriving assessment should identify stroke patients with potential to resume safe driving (Kumar et al, 1991). The aim of this study was to identify the variable or combination of variables from the predriving assessment as performed in Belgium, which best predict the decision of driving ability in stroke patients.

\section{DESIGN}

The records of all patients who visited the CARA section of the Belgian Institute for Road Safety in the year 1998 and 1999 for the first time were reviewed. Patients were selected if they had a history of first stroke, possessed a valid driver's license and had been driving before the stroke onset. Patients with visual field problems before October 11998 were excluded from the study because the law in Belgium (Van Den Meerschaut, 1998), until $1^{\text {st }}$ of October 1998, forbade patients with a visual field problem such as hemianopia after brain damage to resume driving. In all, one hundred and four subjects were included in the study.

\section{MEASURES}

Variables such as age, sex, side of lesion, driving experience, visual acuity, kinetic vision, stereoscopy, neuropsychological assessments most of which are from the Test for Attentional Performance (TAP) battery and an 'on the road' test were considered. Based on the performances of subjects in the tests, a suitable, not immediately suitable or not suitable to drive decision was jointly taken by a team of professional assessors. The team was made up of neurologists, occupational therapists and neuropsychologists in the CARA (Center for determination of fitness to drive and car adaptations) unit of the Belgian Institute for Road Safety.

\section{RESULTS}

Analysis of general data revealed that the variables of age, interval between onset of stroke and examination, driving experience and visual field problem $(p<0.005)$ were significantly different between the three groups of decision. All aspects of the visual test battery and most variables of the neuropsychological test ( $p$-values varying between 0.04 to $<0.0001$ ) were also significantly different between the three groups.

Further comparisons revealed that the variables of age and driving experience (Tukey/Kramer test, $p<0.05$ ) and interval between onset of stroke and examination (Wilcoxon Rank Sum test with Bonferroni correction, $p<0.0167$ ) differentiated between the subjects found either suitable or not immediately suitable to drive from subjects found not suitable to drive. For all neuropsychological tests, similar results were found i.e. significant differences were found between the patients who were either suitable to drive or not immediately suitable to drive and those found not suitable to drive (Tukey/Kramer test, $p<0.05$ and Wilcoxon Rank Sum test with Bonferroni correction, $p<0.0167)$. The visual tests with the exception of acuity of the left and right eyes, differentiated only between subjects found suitable to drive versus those not suitable to drive (Wilcoxon Rank Sum test with Bonferroni correction, $p<0.0167$ ). The on the road test differentiated between all the three groups (Tukey/Kramer test, $p<0.05$ ). Subjects found suitable to drive performed markedly better compared to the other two categories (not immediately suitable to drive and not suitable to drive). 
Relationships between the predriving assessment and the decision to drive as well as the on the road test were further explored using correlation coefficients. General parameters with the exceptions of sex, side of lesion and aphasia had small but significant associations with the group decision ( $r_{s}$ varying between -0.24 and -0.36 ). Correlation coefficients of all items of the visual test battery were found to be significant. Kinetic vision showed the highest association with group decision $\left(r_{s}=0.43\right)$. Most of the neuropsychological tests correlated significantly with the decision to drive. The on the road driving test showed the highest association with the final group decision $\left(\mathrm{r}_{\mathrm{s}}=-0.67\right)$.

Following a logistic regression analysis of 93 complete data sets, a combination of side of lesion, kinetic vision, visual scanning and the 'on the road' test led to the best model in predicting the final group decision $\left(\mathrm{R}^{2}=0.53\right)$. The on the road driving test was the most important determinant $\left(\mathrm{R}^{2}=0.42\right)$. The odds ratio indicates that subjects who improve by five points in the on the road test are two times more likely to be found suitable to drive.

Table 1: Selected model by logistic regression in predicting the final group decision

\begin{tabular}{llllll}
\hline Variables & $\begin{array}{l}\text { Parameter } \\
\text { estimate }\end{array}$ & $\begin{array}{l}\text { Standard } \\
\text { error }\end{array}$ & $\begin{array}{l}\text { Wald Chi- } \\
\text { square }\end{array}$ & $P$ - value & Odds ratio \\
\hline Side of lesion & -1.23 & 0.52 & 5.55 & 0.02 & 0.29 \\
Kinetic vision & 0.81 & 0.32 & 6.51 & 0.01 & 2.25 \\
Scanning & -0.16 & 0.08 & 4.15 & 0.04 & 0.85 \\
On the road test (5 units) & -0.14 & 0.03 & 28.55 & 0.00 & 2.02 \\
\hline
\end{tabular}

$\mathrm{N}=93, \mathrm{R}^{2}=0.53$

\section{DISCUSSION}

Many variables had individual predictive values for the final group decision as shown by the comparison of means, medians or frequencies and the correlation coefficients. Further examination of these results showed that the neuropsychological tests differentiated mainly between those found not suitable and the two other categories. On the other hand, the subjects found suitable to drive performed much better in the on the road test. These findings suggest that subjects in the not immediately suitable to drive category performed well in the neuropsychological tests but rather bad in the on the road driving test. This was probably due to poor compensatory mechanisms during driving.

\section{CONCLUSION}

The on the road driving test was the most important determinant of the decision to drive. The predictive accuracy of the decision to drive was modest. It was therefore suggested that other neuropsychological tests more closely related to road situations be included as part of the predriving assessment. A training program for subjects in the not immediately suitable to drive category aimed at teaching compensatory techniques during driving is currently been developed. 


\section{ACKNOWLEDGEMENTS}

The primary author expresses profound appreciation to the Belgian Institute for Road Safety, Brussels, Belgium particularly the CARA section, for funding support to participate at the conference. The author also acknowledges the Interfaculty Council for Development Cooperation Scholarships Programme of the Katholieke Unversiteit Leuven, Belgium for funding support of his doctoral education.

\section{REFERENCES}

1. Bramford J, Sandercock P, Dennis M. A prospective study of acute cerebrovascular disease in the community: the oxfordshire community stroke project. 1. Methodology, demography and incident cases of first-ever stroke. J Neurol Neurosurg Psychiatry 1988;51:1373-80.

2. Duncan PW, Goldstein LB, Matchar D, Divine GW, Feussner J. Measurement of motor recovery after stroke: outcome assessment and sample size requirements. Stroke 1992;23:1084-9.

3. Kumar R, Powell B, Tani N, Naliboff B, Metter EJ. Perceptual dysfunction in hemiplegia and automobile driving. The Gereontologist 1991;31:807-10.

4. Mazer BL, Korner-Bitensky NA, Sofer S. Predicting ability to drive after stroke. Arch Phys Med Rehabil 1998;79:743-50.

5. Sundet K, Goffeng L, Hofft E. To drive or not to drive: neuropsychological assessment for driver's license among stroke patients. Scan J of Psych 1995;36:47-58.

6. Van Casteren V, Stroobant A, Lobet MP, Cornelis R. Cerebrovasculaire accidenten in België: een epidemiologische studie. Tijdschrift voor geneeskunde 1988;44:1065-70.

7. Van Den Meerschaut C. Rijgeschiktheid. Belgium: Semper October 1998;226:1-35. 